\title{
THE INFLUENCE OF AUTOMATIC FLAP GATE ON EROSION IN TIDAL SWAMP AREA
}

\author{
ACHMAD SYARIFUdIN* \\ Civil Engineering Faculty, Universitas Bina Darma, Jl. Jend. A.Yani No. 12, South Sumatera, \\ Indonesia \\ *Corresponding author: achmad.syarifudin@binadarma.ac.id \\ (Received: 11 January 2022; Accepted: 16 February 2022; Published on-line: 01 July 2022)
}

\begin{abstract}
This research aims to examine the problem of erosion and sedimentation in canals in swampy areas in South Sumatra, namely the P8-13S scheme of the canal (SPD) Telang I, Banyuasin regency with the influence of flap gate. The research method used is to perform simulations in the laboratory using a scale model and related parameters, such as velocity (v), depth of erosion (de), sedimentation (ds), water density ( $\rho$ w), gravitation $(\mathrm{g})$, time (t) and distance (x). Dimensional analysis to determine the related parameters that produce a dimensionless parameter relationship model is carried out using the Langhaar method. The result of the study was that the maximum relative erosion $(\mathrm{de} / \mathrm{t})_{\max }$ occurred at the canals estuary near the flap gate, which was 0.255 during simulation times of 5 minutes. While the maximum relative sedimentation (dd/t)max also occurred at the estuary of the secondary canals (SPD) of 0.05 for 5 minutes. So, the sediment transport process in the secondary canal (SPD) is generally influenced by flow velocity and the presence of a flap gate in the canal to regulate sediment transport.
\end{abstract}

KEYWORDS: SPD Channels, Sluice-gate, Langhaar Method, Sediment Transport.

\section{INTRODUCTION}

In river management, it will be related to sediment transport, which will take into account the magnitude of the dominant discharge. The definition of dominant discharge is discharged that drains most of the suspended sediment in a cross-section river to reach its equilibrium condition [1]. Sediment discharge will be related to river discharge in the form of a discharge-duration curve between the water discharge and the suspended sediment discharge. In contrast, the sediment settlement is directly proportional to the suspension discharge [2], [3].

The flow of water flowing in rivers is not fixed but constantly changes according to a function of time. So the river flow is not permanent (non-steady flow). The sediment intensity will also change according to changes in the discharge, so the amount of total sediment transport is the integration of sediment transport over a certain time [4]. The best approach to forecasting the transport intensity is to use statistical analysis of the flow data [5].

The erosion and sedimentation process greatly affect the balance of the riverbed configuration [4]. The factors forming the configuration of the riverbed are strongly influenced by the speed, duration of flow and depth of flow [6]. Observing the basic material and flow conditions can predict the possibility of sedimentation and erosion/scouring at the riverbed at certain locations in the river channel [7]-[9]. 
A swamp area can be defined as an area that is constantly inundated or at a certain time inundated due to poor or non-existent natural drainage systems [10]. The swamp area that occurs is un-limited by the height (elevation) of the land [11]. Even at high altitudes, swampy areas can be found in areas of geological depression. Stagnant water in this depression area occurs because of the accumulation of rainwater runoff in the basin; water circulation can occur due to evaporation and additional through groundwater [12].

The swamp area has hydrological importance for the physical environment of the river hydrological system [13]. The swamp area in a river flooded area can function as a filter to purify water before it enters the river[14]. Runoff water from higher areas flows into the swamp area. Due to the presence of vegetation in the swamp area, the flow velocity becomes small, which results in the deposition of suspended sediments [15].

Therefore by the time, it left the swamp area, the water had become clearer. Fresh water in swampy areas is a breeding ground for various types of fish and birds and is a source of drinking water for wild animals during the dry season, especially during droughts. The swamp area can also function as a water reservoir that can maintain the presence of groundwater in the area above it [16].

Swamp is land with a relatively flat slope accompanied by naturally formed pools of water that occurs continuously or seasonally due to obstructed natural drainage and has physical characteristics [17]: the shape of the land surface is concave, sometimes peaty, chemical characteristics: the lowest degree of acidity of the water and biological characteristics: there are swamp fish, swamp plants, and swamp forest. Swamps are divided into 2 types: tidal swamps located on the coast, near the coast, estuaries, and near river mouths; and non-tidal swamps (inland swamps) or lebak swamps located further away from the coast so that they are unaffected by tides.

In Indonesia, swampland is estimated at 33.4 million ha, about 60\% (20 million ha) of which are tidal swampland, and the remaining $40 \%$ (13.4 million ha) is non-tidal swampland. From the results of the 1984 survey, an area of 9 million ha of tidal swampland was identified for agricultural. Therefore, it is necessary to study channel sedimentation in swamp areas, both tidal and non-tidal swamps. Thus, this research aims to examine the problem of erosion and sedimentation in canals in swampy areas in South Sumatra, namely the P8-13S scheme of the canal (SPD) Telang I, Banyuasin regency with the influence of flap gate.

\section{MATERIALS AND METHOD}

This research was carried out with research location (Fig. 1) in the Hydraulics Field Laboratory (Site-Laboratory) at Bina Darma University with a scale model on a standard flume as shown in Fig. 2.

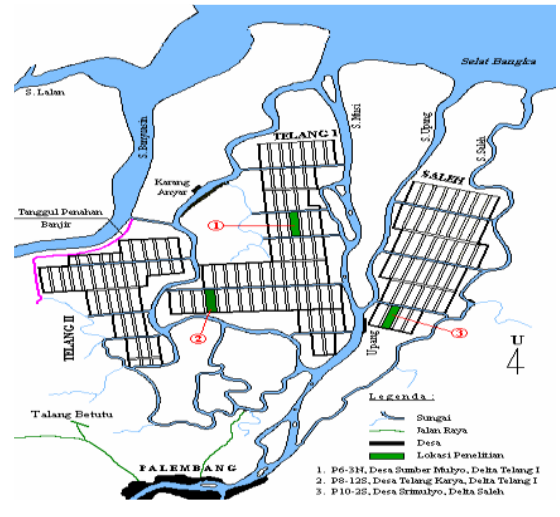


Fig. 1. Research location

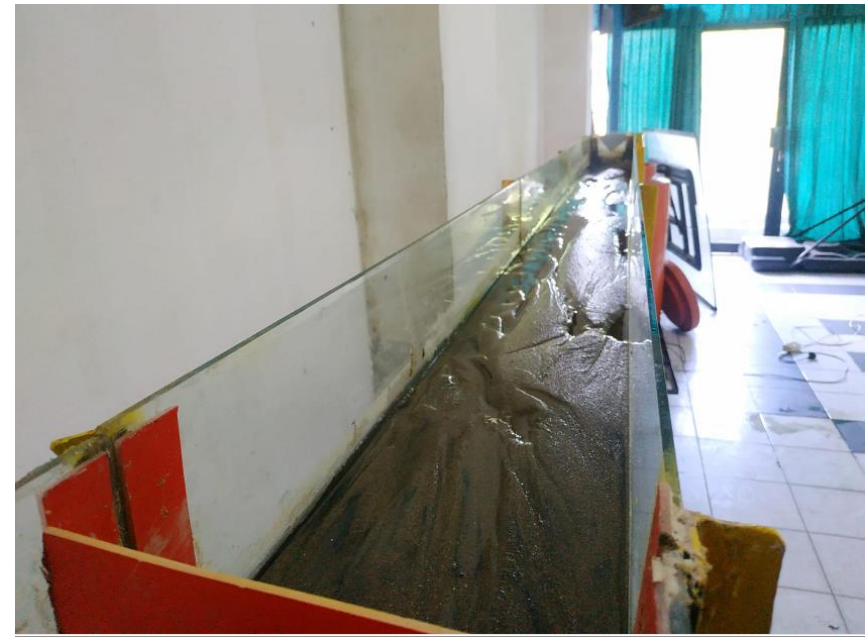

Fig. 2. Two-dimension standard flume

The materials used in this study consisted of:

- Sand with a diameter of $0.025 \mathrm{~mm}$ to $2.36 \mathrm{~mm}$ is considered sedimentary grain material that was previously carried out by sieve analysis to obtain a uniform grain diameter (ds).

- Water flows in the channel as a medium for moving sedimentary material.

Based on Fig. 2, the specifications of the flume: Wall material is glass (Plexiglas); Effective length of $4 \mathrm{~m}$; Width of $0.15 \mathrm{~m}$; Depth of $0.2 \mathrm{~m}$, And automatic valve door. The research model is made by making a scalable model in the laboratory with various flow rate variations, flow rate, and time. The standard flume is mainly made of glass and has the following parts:

- Standard channel is the main part to drain water. In the form of a rectangular channel with $400 \mathrm{~cm}$ x $20 \mathrm{~cm}$ x $15 \mathrm{~cm}$. This channel has transparent walls for easy viewing;

- A reservoir that serves to accommodate water that will flow into the channel or out;

- Water pump serves to pump water to be distributed along the channel. This pump is also equipped with an automatic on and off switch for 220/240 V, $50 \mathrm{~Hz}$;

- The discharge control valve is a faucet that regulates the amount of discharge that comes out of the pump. Has a discharge opening scale of 6-9 range;

- Slope adjustment wheel, located upstream and downstream of the channel, can be turned manually to adjust the desired bed slope. This bed slope control wheel has a scale for a maximum positive bed slope of $+3.0 \%$ and a maximum negative bed slope of $-1.0 \%$.

The dimensions of the variables contained in the field of hydraulic engineering, the MLT system is usually used, namely the writing of dimensions using 3 main elements of the dimensions Mass (M), length (L) and Time (T).

The model is usually done to reduce the various variables by giving a scale (n) on each of these variables. Meanwhile, the scale of the various variables or parameters can be determined based on the relationship between the parameters expressed in dimensionless numbers, such as Reynolds number, Froude number, etc. 
In addition to determining the relationship between scales, this dimensionless number can also be used to describe research results thus the results of these studies can be generalized to determine the dimensionless number can be done by dimensional analysis. Dimensional analysis to determine the dimensionless number has several ways: Basic echelon matrix; Buckingham (phi. theorem); Rayleigh; Stepwise; and Langhaar.

If the hydraulic phenomenon/event can be explained by $\mathrm{n}$ parameters $\mathrm{Pi}$ with $\mathrm{i}=1,2,3$, to $\mathrm{n}$ and if the parameter is composed of $\mathrm{m}$ principal elements, then the product of dimensionless numbers can be derived number $(n-m)$. For hydraulic engineering purposes, there are usually 3 main elements, namely: mass $(\mathrm{M})$, length $(\mathrm{L})$, and time $(\mathrm{T})$.

$$
\pi_{j}=P_{1}^{k_{1}} \cdot P_{2}^{k_{2}} \cdot P_{3}^{k_{3}} \cdots P
$$

where $\pi$ is a product of dimensionless number.

When Pi has dimension $\mathrm{M}$, then the dimensions can be written as follows:

$$
\begin{aligned}
& \pi=\left(M^{\alpha_{1}} \cdot L^{\beta_{1}} \cdot T^{\tau_{1}}\right)^{k_{1}} \cdot\left(M^{\alpha_{2}} \cdot L^{\beta_{2}} \cdot T^{\tau_{2}}\right)^{k_{2}} \cdot\left(M^{\alpha_{n}} \cdot L^{\beta_{n} \cdot T^{\tau_{n}}}\right)^{k_{n}} \\
& \pi=\left[M^{\left(\alpha_{1} k_{1}+\alpha_{2} k_{2}+\alpha_{n} k_{n}\right)}\right] \cdot\left[L^{\left(\beta_{1} k_{1}+\beta_{2} k_{2}+\beta_{n} k_{n}\right)}\right] \cdot\left[T^{\left(\tau_{1} k_{1}+\tau_{2} k_{2}+\tau_{n} k_{n}\right)}\right]
\end{aligned}
$$

$\pi$ is a dimensionless number if

$$
\begin{aligned}
& 0=\alpha_{1} k_{1}+\alpha_{2} k_{2}+\alpha_{n} k_{n} \\
& 0=\beta_{1} k_{1}+\beta_{2} k_{2}+\beta_{n} k_{n} \\
& 0=\tau_{1} k_{1}+\tau_{2} k_{2}+\tau_{n} k_{n}
\end{aligned}
$$

Coefficients $\alpha_{i}, \beta_{\mathrm{i}}$ and $\tau_{\mathrm{i}}$ can be known from Pi's related parameters.

In this research, the dimensional analysis used the Langhaar method because there are few parameters involved. The relationship between the related parameters and the results is in the form of dimensionless parameters.

\section{RESULTS AND DISCUSSION}

From Fig. 3, the maximum relative erosion depth (de/t) max $_{\text {of }} 0.255$ occurs at the mouth of the channel, then up to a relative distance $(\mathrm{x} / \mathrm{t})$ of 80 , the erosion value $(\mathrm{de} / \mathrm{t})$ is 0.05 . with a coefficient of determination R2 of 0.663 or an R-value of $81.24 \%$, it means that distance (x) and time $(\mathrm{t})$ simultaneously have a significant effect on the depth of erosion (de) that occurs.

From Fig. 4, the maximum relative erosion depth $\left(\mathrm{d}_{\mathrm{e}} / \mathrm{t}\right)_{\max }$ of 0.10 occurred at the estuary of the secondary channel (SPD) to a relative distance (x/t) of 25, neither erosion nor sedimentation occurred. This condition is called the balance condition in the channel or "equilibrium". With a coefficient of determination $\mathrm{R}^{2}$ of 0.666 or an R-value of $81.60 \%$, it means that distance $(\mathrm{x})$ and time $(\mathrm{t})$ simultaneously have a significant effect on the depth of erosion $\left(d_{e}\right)$ that occurs.

From Fig. 5, the maximum relative erosion depth $\left(\mathrm{d}_{\mathrm{e}} / \mathrm{t}\right)_{\max }$ of 0.07 occurs at the mouth of the secondary channel (SPD), and a relative distance (x/t) between 10-20 sedimentation occurs in the secondary channel. Then, another relative erosion $\left(\mathrm{d}_{\mathrm{e}} / \mathrm{t}\right)$ of 0.04 at a relative distance $(x / t)$ of 26 . with a coefficient of determination $\mathrm{R}^{2}$ of 0.611 or an $\mathrm{R}$-value of $78.16 \%$, it means that distance $(\mathrm{x})$ and time (t) simultaneously have a significant effect on the depth of erosion (de) that occurs. 


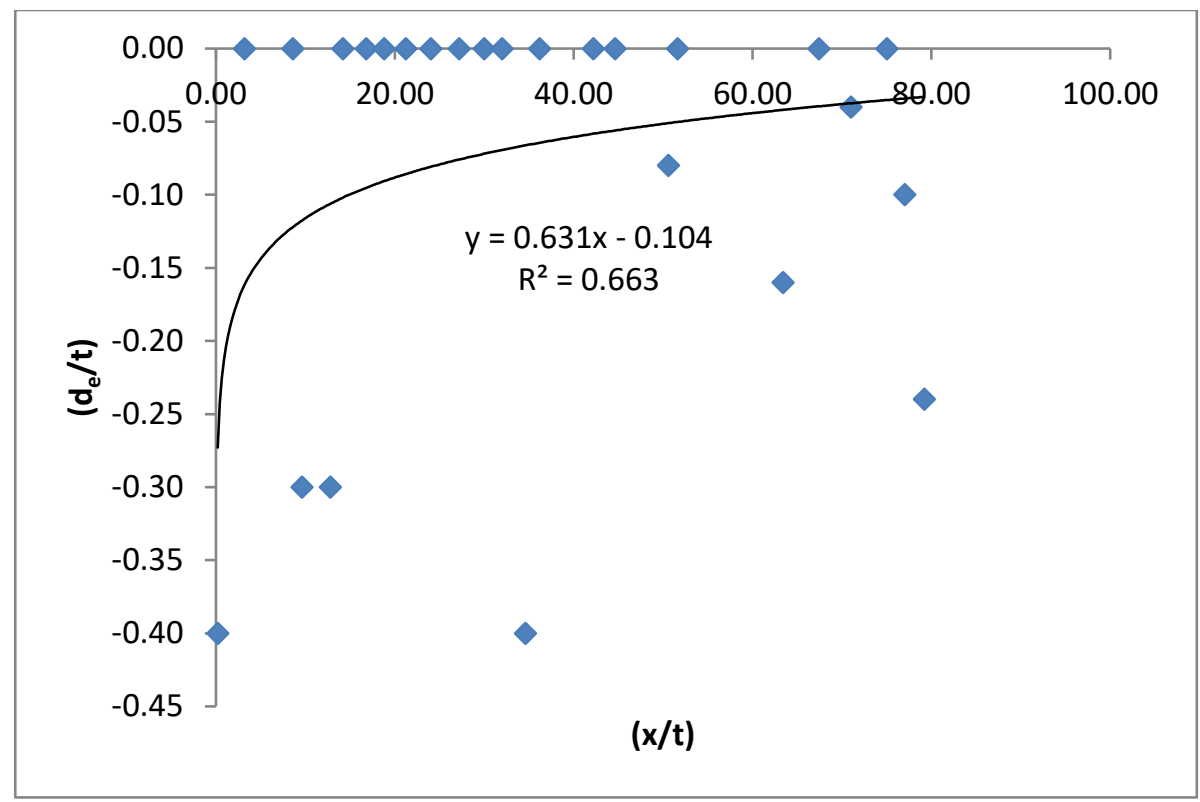

Fig. 3. Test 1 - the relationship between (de/t) and (x/t) during the 5 minute experiment

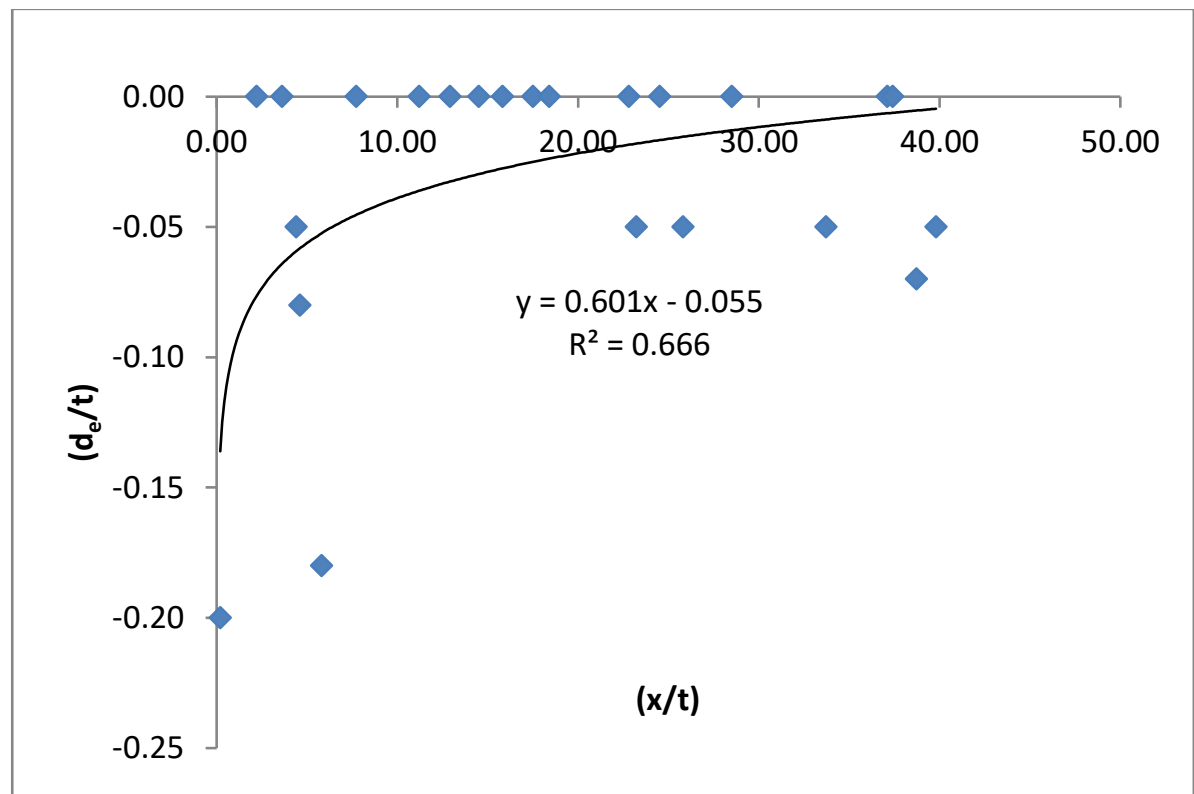

Fig. 4. Test 2 - the relationship between $\left(d_{e} / t\right)$ and $(x / t)$ during the 5 minutes experiment

From Fig. 6, it looks almost the same as the simulation time of 15 minutes, where the maximum relative erosion depth $\left(\mathrm{d}_{\mathrm{e}} / \mathrm{t}\right)_{\max }$ of 0.06 occurs at the estuary of the secondary channel (SPD) and a relative distance (x/t) between 10-15 sedimentation occurs in the secondary channel. Then, another relative erosion $\left(\mathrm{d}_{\mathrm{e}} / \mathrm{t}\right)$ of 0.04 at a relative distance $(\mathrm{x} / \mathrm{t})$ of 20. with a coefficient of determination $\mathrm{R}^{2}$ of 0.628 or an $\mathrm{R}$-value of $79.24 \%$, it means that distance $(\mathrm{x})$ and time $(\mathrm{t})$ simultaneously have a significant effect on the depth of erosion $\left(\mathrm{d}_{\mathrm{e}}\right)$ that occurs. 


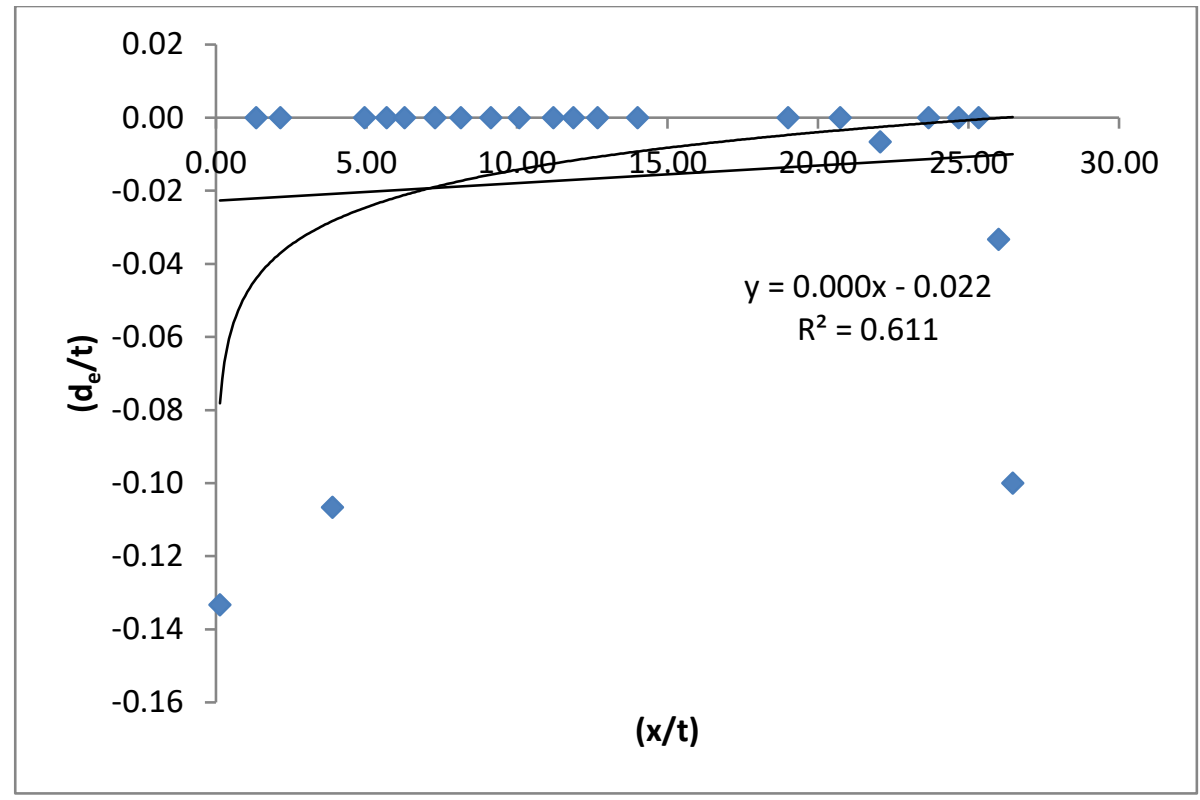

Fig. 5. Test 3 - the relationship between $\left(\mathrm{d}_{\mathrm{e}} / \mathrm{t}\right)$ and $(\mathrm{x} / \mathrm{t})$ during the 5 minutes experiment

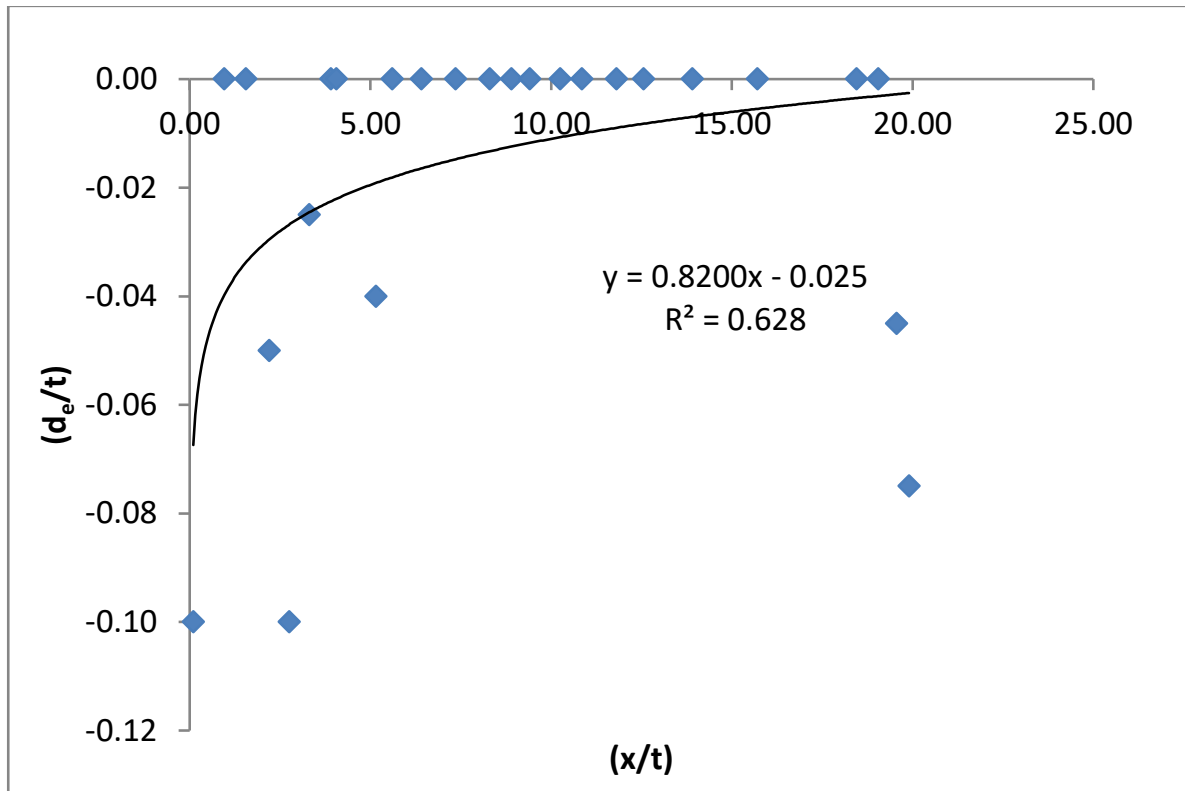

Fig. 6. Test 4 - the relationship between $\left(d_{\mathrm{e}} / \mathrm{t}\right)$ and $(\mathrm{x} / \mathrm{t})$ during the 5 minutes experiment

\section{CONCLUSION}

The maximum relative erosion depth $\left(\mathrm{d}_{\mathrm{e}} / \mathrm{t}\right)_{\max }$ of 0.255 occurs at the mouth of the channel, then up to a relative distance $(\mathrm{x} / \mathrm{t})$ of 80 , the erosion value $\left(\mathrm{d}_{\mathrm{e}} / \mathrm{t}\right)$ is 0.05 . with a coefficient of determination $\mathrm{R}^{2}$ of 0.663 or an $\mathrm{R}$-value of $81.24 \%$, it means that distance $(\mathrm{x})$ and time $(\mathrm{t})$ simultaneously have a significant effect on the depth of erosion $\left(\mathrm{d}_{\mathrm{e}}\right)$ that occurs.

The maximum relative erosion depth $\left(\mathrm{d}_{\mathrm{e}} / \mathrm{t}\right)_{\max }$ of 0.10 occurred at the estuary of the secondary channel (SPD) to a relative distance (x/t) of 25; neither erosion nor sedimentation occurred. This condition is called the balance condition in the channel or "equilibrium". With a coefficient of determination $\mathrm{R}^{2}$ of 0.666 or an R-value of $81.60 \%$, it means that distance (x) and time $(\mathrm{t})$ simultaneously have a significant effect on the depth of erosion $\left(\mathrm{d}_{\mathrm{e}}\right)$ that occurs. 
Almost the same as the simulation time of 15 minutes where the maximum relative erosion depth $\left(\mathrm{d}_{\mathrm{e}} / \mathrm{t}\right)_{\max }$ of 0.06 occurs at the estuary of the secondary channel (SPD), and a relative distance $(\mathrm{x} / \mathrm{t})$ between 10-15 sedimentation occurs in the secondary channel. Then, another relative erosion $\left(\mathrm{d}_{\mathrm{e}} / \mathrm{t}\right)$ of 0.04 at a relative distance $(\mathrm{x} / \mathrm{t})$ of 20 . with a coefficient of determination $\mathrm{R}^{2}$ of 0.628 or an $\mathrm{R}$-value of $79.24 \%$, it means that distance (x) and time ( $\mathrm{t}$ ) simultaneously have a significant effect on the depth of erosion $\left(\mathrm{d}_{\mathrm{e}}\right)$ that occurs.

\section{ACKNOWLEDGEMENT}

Thanks to Universitas Bina Darma for the facilities for this research.

\section{REFERENCES}

[1] F. Aureli and P. Mignosa, "Comparison between experimental and numerical results of 2D flows due to levee-breaking," in Proceedings of the Congress-International Association for Hydraulic Research, 2001, pp. 252-258.

[2] C. Sucipta, H. Wibowo, and D. Gunarto, "Analysis of river geometry on flow discharge in alluvial channels." JeLAST, 2019.

[3] C. Ikhsan, "The effect of variations in flow rate on the bottom of an open channel with uniform flow," Civ. Eng. Media, 2017.

[4] M. S. Yalin, Theory of hydraulic models. Macmillan International Higher Education, 1971.

[5] A. K. Chakraborti, "Strategies for Watershed Management planning using remote sensing technique," J. Indian Soc. Remote Sens., vol. 21, no. 2, pp. 87-97, 1993.

[6] M. Islam, K. Okubo, Y. Muramoto, and H. Morikawa, "Experimental Study on Sedimentation over the Floodplain due to River Embankment Failure," Bull. Disaster Prev. Res. Inst., vol. 44, no. 2, pp. 69-92, 1994.

[7] A. Syarifudin and D. Sartika, "A Scouring Patterns Around Pillars of Sekanak River Bridge," in Journal of Physics: Conference Series, 2019, vol. 1167, no. 1, p. 12019.

[8] A. Syarifudin, "The influence of Musi river sedimentation to the aquatic environment," in MATEC Web of Conferences, 2017, vol. 101, p. 4026.

[9] R. J. Kodoatie, "Flood causes and methods of control in an environmental perspective." 2002.

[10] V. Te Chow, Applied hydrology. Tata McGraw-Hill Education, 2010.

[11] A. E. Bakhshipour, U. Dittmer, A. Haghighi, and W. Nowak, "Hybrid green-blue-gray decentralized urban drainage systems design, a simulation-optimization framework," $J$. Environ. Manage., vol. 249, p. 109364, 2019.

[12] C. Poleto and R. Tassi, "Sustainable urban drainage systems," Drain. Syst., pp. 55-72, 2012.

[13] A. Syarifudin and H. R. Destania, "IDF Curve Patterns for Flood Control of Air Lakitan river of Musi Rawas Regency," in IOP Conference Series: Earth and Environmental Science, 2020, vol. 448 , no. 1, p. 12054.

[14] W. Wu and Q. Lin, "Nonuniform sediment transport under non-breaking waves and currents," coast. Eng., vol. 90, pp. 1-11, 2014.

[15] C. D. Storlazzi, E. Elias, M. E. Field, and M. K. Presto, "Numerical modeling of the impact of sea-level rise on fringing coral reef hydrodynamics and sediment transport," Coral Reefs, vol. 30, no. 1, pp. 83-96, 2011.

[16] L. C. Van Rijn, "Unified view of sediment transport by currents and waves. II: Suspended transport," J. Hydraul. Eng., vol. 133, no. 6, pp. 668-689, 2007.

[17] W. Zhang, Y. Xu, Y. Wang, and H. Peng, "Modeling sediment transport and river bed evolution in river system," J. Clean Energy Technol., vol. 2, no. 2, pp. 175-179, 2014. 